\title{
Comprehending and Using the Mathematical Symbols, from a Quantitative Perspective amongst Preschool and $1^{\text {st. }}$ and $2^{\text {nd }}-$ Grade Pre-Service Teachers
}

\author{
Dina Hassidov ${ }^{1}$, Bat-Sheva Ilany ${ }^{2}$ \\ ${ }^{1}$ Talpiot College of Education, Talpiot, Israel \\ ${ }^{2}$ Hemdat Hadarom College, Hemdat, Israel \\ Email: hasidov@netvision.net.il
}

How to cite this paper: Hassidov, D., \& Ilany, B.-S. (2020). Comprehending and Using the Mathematical Symbols, from a Quantitative Perspective amongst Preschool and $1^{\text {st }}$ - and $2^{\text {nd }}$-Grade Pre-Service Teachers. Creative Education, 11, 1572-1579. https://doi.org/10.4236/ce.2020.119115

\section{Received: July 25, 2020}

Accepted: September 5, 2020

Published: September 8, 2020

Copyright (c) 2020 by author(s) and Scientific Research Publishing Inc. This work is licensed under the Creative Commons Attribution International License (CC BY 4.0).

http://creativecommons.org/licenses/by/4.0/

\begin{abstract}
A study using both quantitative and qualitative methods was conducted among pre-service teachers for preschool and pre-service teachers for grade 1 and 2 to see if they understood when and how to use the mathematical symbols "<", ">", and "=". Some had previously participated in a course on the subject. The study showed a significant difference between those who had previously studied the topic and those who had not: the majority of the latter group did not understand that these symbols may be used ONLY in a mathematical sense when comparing quantity and not when comparing graphical images (i.e., different sizes and thicknesses) nor did their use depend on context (graphical vs. numerical comparisons). This particular study was part of a more comprehensive study about the mathematical knowledge of pre-service teachers.
\end{abstract}

\section{Keywords}

Preschool Teachers, Pre-Service Teachers, Mathematics Education, Early Childhood, Mathematical Symbol

\section{Introduction and Theoretical Background}

Many activities for young children include tasks in which they are asked to place mathematical symbols such as $\langle$, $>$, or $=$ between non-mathematical objects. This activity can sometimes lead them to use these symbols incorrectly. For example, a first-grade child wrote: $5<\mathbf{3}$, because "the three is larger in size and thickness than the five". Mathematical language is a special language that is dif- 
ferent from natural language. It is a language of symbols, concepts, definitions, and theorems and must be taught: it does not develop naturally as does the child's mother tongue. In mathematical language, the child learns to recognize numbers as individual objects and understand their similar and different properties. The child perceives numbers as icons with which one calculates and manipulates in various ways (Ilany \& Margolin, 2010). Hiebert (1988) emphasizes the importance of the connection between advanced cognitive processes and understanding written mathematical symbols. His approach relies on, among other things, theories of mathematical psychology.

Children use mathematics in their daily life almost from birth (Charalambous, Panaoura, \& Philippou, 2009) and the current global trend is to present mathematics "formally" at an early age, which helps the development of cognitive thinking, thinking in general, and mathematical thinking in particular. Studies have shown a correlation between the quantity and quality of math practice in pre-primary schools and the child's success in math in elementary school (Clements \& Sarama, 2015). Today, preschool teachers must have adequate knowledge of teaching mathematics in kindergarten and grades 1 and 2, and it is important that pre-school teachers have appropriate mathematical background and knowledge (Mulligan, 2016).

Recent studies indicate that preschool and early-childhood teachers find themselves lack proper understanding to teach mathematical concepts in early childhood (Hassidov \& Ilany, 2015, 2017); thus, this study aims to understand how pre-service teachers (PST) for primary school (PST-P) and for grades 1 and 2 (PST-12) perceive and use the mathematical relational symbols $<,>$, =. This article presents part of a comprehensive study that examines perceptions of the relational symbols $(<>,=)$ in four categories: numbers; quantity; quantity and numbers; and volume, space, and quantity. In this article, we discuss the second category: quantity.

\section{Research Questions}

1) How do pre-service teachers (PST) and PST-12 perceive and use $<,>$, and $=$ ?

2) Are there differences between PST-P and PST-12 (who have not learned the subject previously) in how they perceive and use $<,>$, =?

3) What are the differences between PST-12 who have studied the subject (PST-12s) compared to PST-12 who have not studied the subject (PST-12ns) in the manner in which they comprehend and use $<,>$, =.

\section{Method}

\subsection{Population}

Study population: A total of 158 PST: 71 PST-P (44.9\% of the total), 87 PST-12 (55.1\%) of which 31 (19.6\% of total) had studied in their first year of studies a semestral course about early childhood mathematics that discussed the 
mathematical relational terms, $<>$, and $=$. The remaining 56 PST-12 (35.4\%) did not participate in this course. (Note, PST-12s indicates those who took the course; PST-12ns indicates those who did not.) During the course of this research, all participants (in their second or third year of studies) participated in a year-long course dealing with pedagogy, teaching, and learning mathematics in early childhood.

\subsection{Research Tools}

The study used both quantitative and qualitative methods.

Questionnaire: A questionnaire composed by the research team that comprised 25 questions. It was used to collect quantitative and qualitative information. This article discusses four of questions from the quantitative domain. The questions are shown in Table 1. Participants were asked to place $<$, >, =, or X (if none of the first three were appropriate) between graphical images and explain their actions.

Interviews: Partially structured interviews of 25 random PST were used to clarify the explanations noted in the questionnaire. A classroom discussion later discussed the use and significance of these symbols and their role in the early childhood mathematics curriculum.

\section{Results}

A breakdown of the distribution of answers comparing PST-P to PST-12 is also shown in Table 1. Results show none of the PST-P gave the correct answer (X). A total of $34.48 \%$ of the PST-12 did answer correctly, and this can probably be attributed to the fact that 31 PST-12 had been taught the subject previously. In fact, $65.52 \%$ of the PST-12ns marked the questionnaire incorrectly with ">”, compared with $0 \%$ of the PST-P. None of the PST-12 gave ">" as the answer, as opposed to $100 \%$ of the PST-P.

Table 1. Percent distribution of answers given to questions about quantity. The correct answer to all questions is $\mathrm{X}$.

\begin{tabular}{|c|c|c|c|c|c|c|c|c|c|c|}
\hline & & & \multicolumn{8}{|c|}{ Answers $(\%, \mathrm{~N})$} \\
\hline & \multicolumn{2}{|c|}{ Questions } & \multicolumn{2}{|c|}{$>$} & \multicolumn{2}{|c|}{$<$} & \multicolumn{2}{|c|}{$=$} & \multicolumn{2}{|c|}{$\mathrm{X}$} \\
\hline & & & PST-12 & PST-P & PST-12 & PST-P & PST-12 & PST-P & PST-12 & PST-P \\
\hline 1 & ;:) & (;):-; & $\begin{array}{c}0 \\
\mathrm{~N}=0\end{array}$ & $\begin{array}{c}100 \\
\mathrm{~N}=71\end{array}$ & $\begin{array}{c}65.52 \\
\mathrm{~N}=57\end{array}$ & $\begin{array}{c}0 \\
\mathrm{~N}=0\end{array}$ & $\begin{array}{c}0 \\
\mathrm{~N}=0\end{array}$ & $\begin{array}{c}0 \\
\mathrm{~N}=0\end{array}$ & $\begin{array}{c}34.48 \\
\mathrm{~N}=30\end{array}$ & $\begin{array}{c}0 \\
\mathrm{~N}=0\end{array}$ \\
\hline 2 & ;):-; & (;);:; & $\begin{array}{c}0 \\
\mathrm{~N}=0\end{array}$ & $\begin{array}{c}0 \\
\mathrm{~N}=0\end{array}$ & $\begin{array}{c}2.30 \\
\mathrm{~N}=2\end{array}$ & $\begin{array}{c}6 \\
\mathrm{~N}=4\end{array}$ & $\begin{array}{c}62.07 \\
\mathrm{~N}=54\end{array}$ & $\begin{array}{c}94 \\
N=67\end{array}$ & $\begin{array}{c}35.63 \\
\mathrm{~N}=31\end{array}$ & $\begin{array}{c}0 \\
\mathrm{~N}=0\end{array}$ \\
\hline 3 & $\frac{8}{89}$ & zigage & $\begin{array}{c}2.30 \\
\mathrm{~N}=2\end{array}$ & $\begin{array}{c}96 \\
N=68\end{array}$ & $\begin{array}{c}62.07 \\
\mathrm{~N}=54\end{array}$ & $\begin{array}{c}1 \\
N=1\end{array}$ & $\begin{array}{c}0 \\
\mathrm{~N}=0\end{array}$ & $\begin{array}{c}3 \\
N=2\end{array}$ & $\begin{array}{c}35.63 \\
\mathrm{~N}=31\end{array}$ & $\begin{array}{c}0 \\
\mathrm{~N}=0\end{array}$ \\
\hline 17 & & & $\begin{array}{c}0 \\
\mathrm{~N}=0\end{array}$ & $\begin{array}{c}0 \\
\mathrm{~N}=0\end{array}$ & $\begin{array}{c}3.49 \\
\mathrm{~N}=3\end{array}$ & $\begin{array}{c}4 \\
N=3\end{array}$ & $\begin{array}{c}55.81 \\
\mathrm{~N}=49\end{array}$ & $\begin{array}{c}90 \\
\mathrm{~N}=64\end{array}$ & $\begin{array}{c}40.7 \\
\mathrm{~N}=35\end{array}$ & $\begin{array}{c}6 \\
N=4\end{array}$ \\
\hline
\end{tabular}


Table 2 further breaks down the distribution of answers into the three groups in the study: PST-P, PST-12s, and PST-12ns. Note that for each of the questions, the correct answers were given primarily by PST-12s. Comparing PST who responded correctly with those who responded incorrectly, the Pearson Chi-Square Test indicates that the percent of the PST-12s group is significantly higher $(P<$ 0.001) than the other two.

Table 3 gives a more in-depth look at the reasons given for the answers given.

For question 1, 100\% of PST-P and PST-12ns gave incorrect answers (100\%). On the other hand, $95.4 \%$ of the PST-12s gave the correct answer. Of the PST-12 who explained their (correct) answer, $87.08 \%$ gave the correct explanation. An example: "Drawings to not represent numbers, and the symbols $\rangle,<$, and = can only be used for quantitative numbers." Another: "I indicated $X$ because one cannot use the symbols for graphical images. However, if they are changed to numbers, then one can use the symbols of $>,<,-$. " However, some "correct answers" were correct for the wrong reason. For example: "The pictures do not represent numbers because they are not accurate." Among the PST-P and the PST-12 who answered incorrectly, the most common explanation was the quantitative aspect, that is to say, they referred to the number of faces. For example, "The right rectangle has 3 smileys, and the left has two. So, mathematically speaking, the right one has more."

Table 2. Comparison of the distribution of answers among the three groups of PST (Note. The correct answer to all questions is “X”)

\begin{tabular}{|c|c|c|c|c|c|c|c|c|c|}
\hline & & PST-P & & & PST-12ns & & & PST-12s & \\
\hline Answer & $\mathrm{N}$ & $\%$ of sample & $\%$ of PST & $\mathrm{N}$ & $\%$ of sample & $\%$ of PST & $\mathrm{N}$ & $\%$ of sample & $\%$ of PST \\
\hline$<$ & 71 & $55.5 \%$ & $100.0 \%$ & 55 & $43.0 \%$ & $98.2 \%$ & 2 & $1.6 \%$ & $6.5 \%$ \\
\hline \multirow{3}{*}{1} & 0 & $0.0 \%$ & $0.0 \%$ & 0 & $0.0 \%$ & $0.0 \%$ & 0 & $0.0 \%$ & $0.0 \%$ \\
\hline & 0 & $0.0 \%$ & $0.0 \%$ & 0 & $0.0 \%$ & $0.0 \%$ & 0 & $0.0 \%$ & $0.0 \%$ \\
\hline & 0 & $0.0 \%$ & $0.0 \%$ & 1 & $3.3 \%$ & $1.8 \%$ & 29 & $96.7 \%$ & $93.5 \%$ \\
\hline \multirow{4}{*}{2} & 0 & $0.0 \%$ & $0.0 \%$ & 1 & $100.0 \%$ & $1.8 \%$ & 0 & $0.0 \%$ & $0.0 \%$ \\
\hline & 4 & $100.0 \%$ & $5.6 \%$ & 0 & $0.0 \%$ & $0.0 \%$ & 0 & $0.0 \%$ & $0.0 \%$ \\
\hline & 67 & $55.4 \%$ & $94.4 \%$ & 52 & $43.0 \%$ & $94.5 \%$ & 2 & $1.7 \%$ & $6.5 \%$ \\
\hline & 0 & $0.0 \%$ & $0.0 \%$ & 2 & $6.5 \%$ & $3.6 \%$ & 29 & $93.5 \%$ & $93.5 \%$ \\
\hline \multirow{4}{*}{3} & 68 & $55.7 \%$ & $95.8 \%$ & 53 & $43.4 \%$ & $94.6 \%$ & 1 & $0.8 \%$ & $3.2 \%$ \\
\hline & 1 & $33.3 \%$ & $1.4 \%$ & 2 & $66.7 \%$ & $3.6 \%$ & 0 & $0.0 \%$ & $0.0 \%$ \\
\hline & 2 & $100.0 \%$ & $2.8 \%$ & 0 & $0.0 \%$ & $0.0 \%$ & 0 & $0.0 \%$ & $0.0 \%$ \\
\hline & 0 & $0.0 \%$ & $0.0 \%$ & 1 & $3.2 \%$ & $1.8 \%$ & 30 & $96.8 \%$ & $96.8 \%$ \\
\hline \multirow{4}{*}{17} & 0 & $0.0 \%$ & $0.0 \%$ & 0 & $0.0 \%$ & $0.0 \%$ & 0 & $0.0 \%$ & $0.0 \%$ \\
\hline & 3 & $50.0 \%$ & $4.2 \%$ & 3 & $50.0 \%$ & $5.6 \%$ & 0 & $0.0 \%$ & $0.0 \%$ \\
\hline & 64 & $58.2 \%$ & $90.1 \%$ & 45 & $40.9 \%$ & $83.3 \%$ & 1 & $0.9 \%$ & $3.2 \%$ \\
\hline & 4 & $10.0 \%$ & $5.6 \%$ & 6 & $15.0 \%$ & $11.1 \%$ & 30 & $75.0 \%$ & $96.8 \%$ \\
\hline
\end{tabular}


Table 3. Analysis of the percentage of reasons for answers between the three groups of pre-service teachers for questions $1,2,3$, and 17 .

\begin{tabular}{|c|c|c|c|c|c|c|c|c|c|c|c|c|}
\hline \multirow{2}{*}{ PST } & & \multicolumn{5}{|c|}{ Reasons given - Incorrect answers } & \multirow{2}{*}{$\begin{array}{c}\text { Total } \\
\text { incorrect } \\
\text { answers }\end{array}$} & \multicolumn{3}{|c|}{ Reasons given - correct answers } & \multirow{2}{*}{$\begin{array}{c}\text { Total } \\
\text { correct } \\
\text { answers }\end{array}$} & \multirow{2}{*}{$\begin{array}{l}\text { Number of } \\
\text { PST who } \\
\text { answered } \\
\text { the question }\end{array}$} \\
\hline & & $\begin{array}{l}\text { Graphical } \\
\text { aspect }\end{array}$ & Quantitative & $\begin{array}{l}\text { Size and } \\
\text { quantity }\end{array}$ & $\begin{array}{l}\text { No reason } \\
\text { given }\end{array}$ & $\begin{array}{l}\text { Other } \\
\text { reason }\end{array}$ & & $\begin{array}{l}\text { Correct } \\
\text { reason }\end{array}$ & $\begin{array}{c}\text { Incorrect } \\
\text { reason }\end{array}$ & $\begin{array}{c}\text { No reason } \\
\text { given }\end{array}$ & & \\
\hline \multicolumn{13}{|c|}{ Question 1} \\
\hline \multirow{2}{*}{ PST-12ns } & $\mathrm{N}$ & 1 & 48 & 0 & 7 & & 56 & 0 & 0 & 0 & 0 & 56 \\
\hline & $\%$ & 1.79 & 85.71 & 0 & 12.5 & & 100 & 0 & 0 & 0 & 0 & 100 \\
\hline \multirow{2}{*}{ PST-12s } & $\mathrm{N}$ & 0 & 2 & 0 & 0 & & 2 & 27 & 1 & 1 & 29 & 31 \\
\hline & $\%$ & 0 & 6.46 & 0 & 0 & & 6.46 & 87.08 & 3.23 & 3.23 & 93.54 & 100 \\
\hline \multirow{2}{*}{ PST-P } & $\mathrm{N}$ & 1 & 56 & 0 & 14 & & 71 & 0 & 0 & 0 & 0 & 71 \\
\hline & $\%$ & 1.4 & 78.8 & 0 & 19.8 & & 100 & 0 & 0 & 0 & 0 & 100 \\
\hline \multicolumn{13}{|c|}{ Question 2} \\
\hline \multirow{2}{*}{ PST-12ns } & $\mathrm{N}$ & 1 & 45 & 0 & 8 & & 54 & 0 & 2 & 0 & 2 & 56 \\
\hline & $\%$ & 1.79 & 80.35 & 0 & 14.29 & & 96.43 & 0 & 3.57 & 0 & 3.57 & 100 \\
\hline \multirow{2}{*}{ PST-12s } & $\mathrm{N}$ & 0 & 2 & 0 & 0 & & 2 & 27 & 0 & 2 & 29 & 31 \\
\hline & $\%$ & 0 & 6.46 & 0 & 0 & & 6.46 & 87.08 & 0 & 6.46 & 93.54 & 100 \\
\hline \multirow{2}{*}{ PST-P } & $\mathrm{N}$ & 2 & 52 & 7 & 10 & & 71 & 0 & 0 & 0 & 0 & 71 \\
\hline & $\%$ & 2.8 & 73.2 & 9.9 & 14.1 & & 100 & 0 & 0 & 0 & 0 & 100 \\
\hline \multicolumn{13}{|c|}{ Question 3} \\
\hline \multirow{2}{*}{ PST-12ns } & $\mathrm{N}$ & 2 & 43 & 0 & 8 & & 53 & 1 & 1 & 1 & 3 & 56 \\
\hline & $\%$ & 3.57 & 76.77 & 0 & 14.29 & & 94.63 & 1.79 & 1.79 & 1.79 & 5.37 & 100 \\
\hline \multirow{2}{*}{ PST-12s } & $\mathrm{N}$ & 0 & 1 & 0 & 0 & & 1 & 27 & 1 & 2 & 30 & 31 \\
\hline & $\%$ & 0 & 3.23 & 0 & 0 & & 3.23 & 87.08 & 3.23 & 6.46 & 96.77 & 100 \\
\hline \multirow{2}{*}{ PST-P } & $\mathrm{N}$ & 1 & 57 & 1 & 12 & & 71 & 0 & 0 & 0 & 0 & 71 \\
\hline & $\%$ & 1.4 & 80.3 & 1.4 & 16.9 & & 100 & 0 & 0 & 0 & 0 & 100 \\
\hline \multicolumn{13}{|c|}{ Question 17} \\
\hline \multirow{2}{*}{ PST-12ns } & $\mathrm{N}$ & 11 & 17 & 5 & 13 & 2 & 48 & 2 & 0 & 5 & 7 & 55 \\
\hline & $\%$ & 20 & 30.9 & 9.09 & 23.64 & 3.64 & 87.27 & 3.64 & 0 & 9.09 & 12.73 & 100 \\
\hline \multirow{2}{*}{ PST-12s } & $\mathrm{N}$ & 0 & 1 & 0 & 0 & 0 & 1 & 27 & 1 & 2 & 30 & 31 \\
\hline & $\%$ & 0 & 3.23 & 0 & 0 & 0 & 3.23 & 87.08 & 3.23 & 6.46 & 96.77 & 100 \\
\hline \multirow{2}{*}{ PST-P } & $\mathrm{N}$ & 10 & 36 & 4 & 17 & 0 & 67 & 0 & 1 & 3 & 4 & 71 \\
\hline & $\%$ & 14.1 & 50.7 & 5.6 & 23.94 & 0 & 94.34 & 0 & 1.41 & 4.25 & 5.65 & 100 \\
\hline
\end{tabular}

For question 2, all the PST-P and $96.43 \%$ of the PST-12ns gave incorrect answers. In contrast, $100 \%$ of PST-12s answered correctly, $93.54 \%$ of whom gave explanations of which $87.08 \%$ were correct. Among the PST who answered in- 
correctly, the most common explanation was the quantitative aspect, that is to say, they referred to the number of smileys (73.2\% of PST-P, $6.46 \%$ of PST-12s, and $80.35 \%$ of PST-12ns). In addition, $9.9 \%$ of PST-P who answered incorrectly referred to both size and quantity referred in their explanations (compared to 0\% of PST-12). Example explanations for incorrect answers: "I marked $<$ because the rectangle on the right is darker than the other"; "I answered = because the smileys are equal in both rectangles. The difference is the length of the frame." Another PST first marked " $\mathrm{X}$ " and then changed to "=" and explained that "I didn't know to which criterion to relate." Another: "You do not need to consider the size of the lines." An example of an incorrect explanation to a correct answer: "In graphics, one cannot be precise as to whether the drawings are the same size or equal."

For question 3, $100 \%$ of PST-P and $94.63 \%$ of PST-12ns gave incorrect answers. In contrast, $96.77 \%$ of PST-12s answered correctly, $90.31 \%$ of whom gave explanations of which $87.08 \%$ were correct. Among the PST who answered incorrectly, the most common mistake was the quantitative aspect, that is to say, they focused on the flower icon (80.3\% of PST-P, 3.23\% of PST-12s, and $76.77 \%$ of PST-12ns). An example of an incorrect explanation to the correct answer: "One counts the number icons, and the greater number is the answer, without regard to position."

For question 17, 94.34\% of the PST-P and $87.27 \%$ of the PST-12ns gave incorrect answers. In contrast, $96.77 \%$ of PST-12s answered correctly, $90.31 \%$ of whom provided an explanation of which 87.08 gave the correct one. Among the PST who answered incorrectly, the most common mistake was the quantitative aspect, that is to say, they considered the number of triangles (50.7\% of PST-P, $3.23 \%$ of PST-12s, 30.9\% of PST-12ns). Examples of explanations given by PST-12ns (correct answer but incorrect reason): “There is no answer because I didn't know which symbol to put, because on both the right and the left there are two triangles but there is no equality in the way they are arranged"; "It is impossible to know because the exercise can be considered as one with triangles, and as a whole" A PST who indicated = (incorrect) explained: "On each side there are two triangles." Another PST indicated > and wrote: "We calculate the symbols," later explaining in the interview: "On the left side we calculate by adding one triangle with another triangle and that is equal to 2. On the other hand, on the right side, we divide one triangle by one triangle, and this is equal to one. Therefore, the left side is greater than the right side" (see Figure 1).

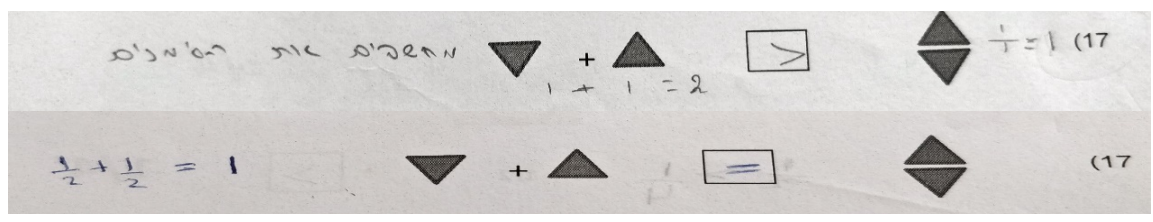

Figure 1. Two examples of how PST derived their answers (both incorrect) for question 17. 


\section{Discussion and Conclusions}

This study revealed that the PST used the mathematical relational symbols in different ways depending on the context: sometimes focusing on quantity, sometimes on the shape or size of the images, and sometimes on graphical aspects, but never did the participants consider the actual mathematical meaning of the relational symbols.

The majority of PST-P and PST-12ns incorrectly perceived the meanings of these symbols (as indicated by the reasons stated and the interviews) and even the PST-12s, many of whom responded correctly, indicated by their reasons and interviews that despite the correct answer, they did not correctly perceive the meaning and use of symbols. It is thus possible to conclude that the majority of PST do not properly understand the meaning and manner of using the relational symbols in the true mathematical sense and therefore, one may assume, will also not teach the issue correctly.

Two types of misunderstandings were found among the participants who had not studied the subject:

1) They did not understand that mathematical symbols relate only to numerical situations, nor did they understand that a graphic object cannot be treated as a number.

2) Even in cases where they answered correctly, the reasoning was incorrect. False perceptions regarding the meaning of the mathematical relational signs can be a result of using identical words in everyday life and in mathematics (Ilany \& Margolin, 2010).

Examples of this are the use of the words "larger than", "smaller than", and "equal" in natural language in everyday life for non-mathematical situations and their use as the mathematical language for the symbols ">", "<", and " =". As one PST said in the interview: "They teach the child to use the '>' symbol between two objects where in one case the size is important and in another case the length may be important. It depends on the context." Another PST stated: "Sometimes, in certain situations, it is appropriate to use two different relational marks simultaneously, for example, once for comparing the sizes of the rectangles and once for comparing the thicknesses of the rectangles." Often, the PST demonstrated inconsistencies: for example, one PST indicated " $\mathrm{X}$ " for both questions 1 and 2 but explained that "the drawings do not represent numbers because they are inaccurate." He indicated different symbols based on quantity in one case, and size in another. Another PST answered "=" for question 2 because "the smileys are equal in both rectangles, the difference is the length of the frame." However, with the other questions, this same student focused on other criteria (Figure 2).

The situation that this leads to is that PST is unaware of the cognitive conflict that occurs when children are encouraged to interpret mathematical symbols in non-mathematical situations. PST must understand that one must not use mathematical relational symbols in situations that are not mathematical and that 


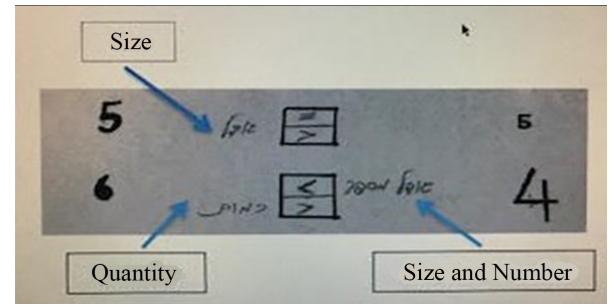

Figure 2. Example of how PST derived an answer.

"<," ">," and "=" must only ever be used to compare numbers or variables.

One possible way of getting PST to understand the significance of these symbols and their use can be through activities that purposely lead to a cognitive conflict, followed by a professional discussion on the subject.

It is important to emphasize that, like any language, the mathematical language has its own rules and symbols-numbers, operational symbols, relational symbols, and more-that enable the language to exist and this awareness must be reinforced among those involved in the teaching of mathematics.

\section{Conflicts of Interest}

The authors declare no conflicts of interest regarding the publication of this paper.

\section{References}

Charalambous, C. Y., Panaoura, A., \& Philippou, G. (2009). Using the History of Mathematics to Induce Changes in Pre-Service Teachers' Beliefs and Attitudes: Insights from Evaluating a Teacher Education Program. Educational Studies in Mathematics, 71, 161-180. https://doi.org/10.1007/s10649-008-9170-0

Clements, D. H., \& Sarama, J. (2015). Developing Young Children's Mathematical Thinking and Understanding. In S. Robson, \& S. Flannery (Eds.), The Routledge International Handbook of Young Children's Thinking and Understanding (pp. 331-344). New York: Routledge.

Hassidov, D., \& Ilany, B. (2015). The "Senso-Math" Preschool Program: Successful Cooperation between Mathematics Facilitators and Preschool Teachers. Proceedings of the 39th Conference of the International Group for the Psychology of Mathematics (Vol. 3, pp. 41-48). Hobart, Australia: PME.

Hassidov, D., \& Ilany B. (2017). Between Natural Language and Mathematical Symbols $(<,>,=)$ : The Comprehension of Pre-Service and Preschool Teachers-Perspective of Numbers. Creative Education, 8, 1903-1911. https://doi.org/10.4236/ce.2017.812130

Hiebert, J. (1988). A Theory of Developing Competence with Written Mathematical Symbols. Educational Studies in Mathematics, 19, 333-355. https://doi.org/10.1007/BF00312451

Ilany, B., \& Margolin, B. (2010). Language and Mathematics: Bridging between Natural Language and Mathematical Language in Solving Problems in Mathematics. Creative Education (CE), 1, 138-148. https://doi.org/10.4236/ce.2010.13022

Mulligan, J. T. (2016). Promoting Early Mathematical Structural Development through an Integrated Assessment and Pedagogical Program. In Program of the 13th International Congress on Mathematical Education Topic Study Group 1: Early Childhood Mathematics Education (p. 44). Hamburg: University of Hamburg. 